\title{
THE EDUCATIONAL ASPECTS OF ART CRITICISM
}

\author{
Ass. Prof. PhD Maya Smolina ${ }^{1}$ \\ Ass. Prof. PhD Maria Tarasova \\ Postgraduate Yuliya Avdeeva \\ Postgraduate Kseniya Degtyarenko \\ Master's degree Anna Shpak
}

\section{Abstract}

The aim of this study is to identify the educational function of art criticism. The importance of the problem is in unrealized educational potential of art criticism in the field of publication activity, in the need for clear principles of creating the educational effect in the texts of art critics. Historiography of art is represented by the works of such European scholars as Hans Sedlmayr, Germain Bazin. In Russian historiography this issue was explored by scholars V. S. Turchin, V. P. Shestakov and V. G. Arslanov. The methodology of the work has been substantiated by the developments of the Ural-Siberian scholars N.P. Koptseva, and V. I. Zhukovsky, D. V. Pivovarov, who have developed a professional model of art criticism, comprising three components (expertise, research and maieutics). Analysis of the characteristics of publications of art critics, comparison with the concept of education and the conception of the profession of art expert has allowed us to detect the relationship between certain features of construction of text of criticism and literary works; we have made some assumptions about what features strengthen the educational effect. Further studies in this area require verification of these assumptions in practice. Finally, we came to the conclusion that the educational focus of the literary text of art criticism leads to the subjects acquiring knowledge about each other and to selfdevelopment of both the artwork as a model of relation in the world and the identity of the person, involved in the artistic communication.

Keywords: art criticism, culture, self-reflection, art.

\section{INTRODUCTION}

\footnotetext{
${ }^{1}$ Siberian Federal University, Russia.
} 
Art criticism is part of art history. In the XVIII century, the science of art manifested itself in three components: theory of art, art history and artistic criticism (art criticism). Historiography of art is represented by the works of such European scholars as Hans Sedlmayr [12], Germain Bazin [2]. In Russian historiography these issues were studied by the scholars V. S. Turchin [11], V. P. Shestakov [10, 14] and V. G. Arslanov [1]. Art criticism has the function of the organ of self-reflection of artistic culture. However, along with the implementation of this cultural goal, the texts of art criticism constitute the educational space. The text of art criticism implies the relationship of the two subjects of art - the work of art and a person. Educational vector of the text of art criticism leads to the subjects acquiring knowledge of each other and to self development of both the work of art as a model of relations in the world, and individuality of a person, involved in art communication.

The text of art criticism performs the function of the educational bridge, which translates the ideal of artistic culture to the person -viewer. The space of such an educational facilitator, as the text of art criticism, presents the most active communication area, in which the work of art and the viewer enter a relationship, preparing a complete educational opening towards each other. Expertise, research and maievtics components of critical text form the patterns of the viewer's activity for the actualization of the work of art as the ideal of artistic culture.

The relevance of the study is that in contrast to the arts studies in general, the specific quality of art criticism is its publicistic component, therefore, it is from this branch of work of the art critic that we should expect the popularization of the art research in verbal texts, addressed to a wide audience of amateur viewers and artists-beginners. However, there is certain art criticism, whose texts are intended for a narrower circle of specialists in the field of art, possessing analytical mindset, and speculative abilities.

The publicist principle of art criticism demonstrates the process of reflection in a materialized form by means of its own forms and genres. By these means the scattered energy of self-reflection of the artistic culture acquires the flesh of the written text, the most "solid" media of internal and external artistic information.

Critical reflection "passes" the first "verdict" regarding the truth of the artistic presentation of the essence in the artwork. This conclusion is further transmitted through the theory and history of art, where it is mastered and tested. This circumstance explains the "avant-gardness" of art publicism in relation to the theory and history of art and "dispersed" critical component in them. 
Art criticism is the active principle in the structure of artistic culture, being the "feedback" in communication between the spheres of art and nonart.

For determining the intersubjective basis of activity of the art critic, the problem of establishing the contact between artistic sphere and the audience is essential.

The critic as "another viewer" means that the critic just offers to the viewer as a partner alternative interpretations and evaluations. The algorithm of his actions in this case approaches the algorithm of actions of the viewer, who is close to him in the degree of talent, experience, and artistic knowledge; the main role is given to the free activity of perception, on receptive co-creation.

The critic as "another artist" means the critic as "another author". Here the critic puts forward alternative ideas to those that are already present in creative background, he is present as a generator of ideas, in the optimal case he becomes the inspirer of a new movement and direction. The mode of action of such criticism, losing the characteristics of co-creation, to some extent approaches creation, taking its properties up to the point, where the general idea helps to predict the nature of future works.

\section{METHODOLOGY AND METHODS}

Using the existing terminology of the theory of the fine arts by V. I. Zhukovskiy and N. P. Koptseva, we can say that these points of literary criticism are manifested in the concepts of "expertise", "research" and "maieutics". In the books of these authors there is a detailed justification of these three components of the professional model of an art expert. [4, 5].

The potential ideal viewer and a work of art have educational relationship. This means that they are involved in the formation of the integrity of each other. The viewer gets the opportunity of forming the integrity as the unity of flesh, soul and spirit. The artwork also gains the ability to be formed into a coherent system of signs, whose meanings are disclosed, that is, to appear as a perceptibly manifested idea. One of the mediators in these educational relations between the viewer and the artwork is art criticism. Educational aspect of this activity is very important for art studies, because development of artistic culture depends on educational relations, since only meeting and educational dialogue with the artwork and the viewer determines its quality. The particular relevance of mediation in the educational process is caused by the existence of problems in the educational relationship between the viewer and the artwork. The causes of these problems are associated with different levels of the recipient of the text 
of art criticism (viewer, artist -author) and different properties of artworks (as the result of the creative process and as a partner in dialogue).

The studies $[3,6,7,8,9]$ contain the classification of the components of a person, common in many religious traditions: a man as a whole consists of flesh, soul and spirit. Applying this to the quality of the viewer we received a one-dimensional viewer, whose vision of objects is dominated by the vision of the flesh; then the viewer becomes two-dimensional, his vision including flesh and spirit; and later the viewer becomes three-dimensional, having achieved the educational ideal, now he is able to see the integrity of flesh, spirit and mind in the work of art. It should be noted that at each of the stages the viewer needs to overcome the obstacle of a barrier of vision (to move from simple reflection of the story to a spiritual dialogue with the work of art, or to form a complete artistic image). This support in overcoming boundaries can be obtained not only through a specially prepared site, such as pedagogical space of the classroom, but also through a verbal text about art.

The verbal text that serves as mediation needs to be both attractive and clear, and it should not replace the literary text. There exists the experience of ekphrasis [15] - artistic description of the work of art. There are some writers-critics (e.g., D. Diderot, D. Ruskin, S. Baudelaire, T. Gautier), adhering to this approach. The basis of this approach is expressed in the fact that an adequate translation from visual to verbal language is impossible in principle, and the emphasis in the description of works of art by art historians often depend on their methodological concepts. In the work of art there always remains something idiomatic, so its adequate expression is possible through the idiom of another (verbal) language. In addition, there is the idea of the existence of the text of art criticism as a comment to art, which ambivalently transmits the state of its necessity (on the one hand) and uselessness for the reader (on the other hand).

\section{RESULTS AND DISCUSSION}

Actions of an art critic consist, first of all, of sifting away the important from the secondary, representational from non-representational in the art space and of carrying out diagnostics of quality of artistry in the work of art $[10,13]$. Secondly, he/she has to be able to generalize, that is to be able to reveal in the single specific work of art the richness of representation of the cultural-esthetic ideal. This "economy of effort", a leap from the single into the multiple artistic and cultural space, gives the overall "spring" to the text of art criticism, provoking a qualitative leap in the consciousness of the reader in overcoming the borders of the former "I". However, the opposite principle should also be at work in the critical text: the collapsing of 
multitude into the singularity (it is, for example, connected with the choice of words, the selection of lexical material): the less and more accurate is preferable. The word as a tool of art criticism, on the one hand, should be as accurate as possible to reflect the very essence and the idea of the work of art, to reduce it to the concise and clear formulae. On the other hand, resembling a true work of art, it should vibrate with meanings, spreading into the infinity. It should be remembered that, side by side with each other, words leave reflections of themselves on the nearby words. In connection with this contextuality of words, adopting a useful experience of art of literature, art criticism needs to test the relationship of words to each other, their behavior in the structure of phrases, the new illumination in light of the emerging content of the text. In this case, the text of art criticism serves as an educational intermediary in connection with the modeling of the verbal integrity of the word fabric.

Verbalization of the idea of artwork is a good example, possessing ideal qualities, that one is tempted to use as an example of the way to express the ideas in communication with the work of art.

Because the critical text is a text about text, a work about a piece of artwork, it is naturally characterized by intertexuality, when the addresser (the sender of the message) uses other texts, playing with them, quoting or translating from another language. This organization of this intertextuality also allows you to create a rhythm of "diving" (plunging) and "emerging" (estrangement) in some primary texts that start talking on their own.

Parallelization of sentences, unity of paragraphs, the ring method of the composition, - all this allows to set the desired "anchor" of the association in the reader's mind to engage a kind of mnemonics, in which repetitions play the role of "hooks" of attention. At the right moment of a meeting of the recipient with the work of art this "anchor", when activated, causes the necessary associations and enriches personal discoveries, stimulated by the text of art criticism.

The text of art criticism must use the language that is convenient and close to the level of the recipient, and to strive, nevertheless, to cultivate the reader, by modelling a language educational situation. The same principle of increasing the level of the reader can be used with the special terminology. "Overloading" the reader with technical terms, as well as "an avalanche" of facts, names, and numbers may cause the reader's rejection. Excessive minute, "antique" and "jewelry" details, lots of nuances in the text can also cause fatigue in the reader instead of fun. The special terminology should be used to engage the reader, to encourage him/her to obtain knowledge on his/her own, cause a positive attitude to the sense of extension of not only the boundaries of their knowledge, but also the limits of their mind, thinking, 
ideas about themselves and the world. The first plane of mediation between the art criticism in educational relations is connected with knowledge (expertise) aspect of art studies' activities, it is the expansion of knowledge of the reader in the artistic and cultural sphere. However, it is not only knowledge of facts, but also the development of methods for obtaining knowledge about how to identify authentic art or false one.

The second plane of mediation of art criticism is associated with the fact, that criticism promotes the education leap of the artist, self-reflecting on his/her creative path. However, the second subject of creativity, which is artistic material, also needs a critical look, which will reflect its properties, relevance, degree of realization or inexhaustibility, opportunities and constraints.

The third plane of criticism can be associated with complex skills in organizing the laboratory of self-discovery of the viewer and the artwork, each of which requires self-assessment: identifying one's own level of viewing and one's own opportunities for a productive dialogue with the work of art, positioning the artwork in the system of works of art. The work of art in this case is understood as the subject of the action, as one of the parties in the dialogue. One of the most effective ways is a specific verbal irony, mastered to perfection by Socrates, which perfectly corresponds to the paradigm of educational maieutics, where the slightly unveiled truth, you can see the glimpses of, covered with a light veil of apparent ignorance, seduces you to tear it off and become the pioneer of discovering the meaning.

The art critic, who has walked the way of the ideal relation with the work of art, which has been modeled by the artist in his play with the art material, makes sure that the lack of experience does not prevent the other viewer from recognizing the suggested path. In the case of the visual arts, the critic by the means of a verbal text, stimulates visual thinking, allowing the viewer to reach different levels of the artwork. On the one hand, the sphere of extrapolation is predetermined by the critic's own viewer's experience of interaction with the artwork; on the other hand, the critic must indicate the spheres of extrapolation, determined by the artist. It means minimizing the decorativeness of verbal presentation that is not intended at awakening visual thinking.

The human community also limits the scope of possible extrapolation by the conventions, imperatives, standards, and ideological trends, existing in this community. For example, the requirements of morality in the age of Enlightenment were very high, which intensified the actual identity of the ethical and aesthetic evaluations. Educators D. Diderot, D. Ruskin were often the sons of their time in understanding the true humanity, from which they drew the scope of extrapolating the knowledge about the standard. 
At first glance, the choice of the reference quality of the artwork is determined by the subjective opinion of the critic. However, criticism of a work of art is the criticism of the "artistic image", which is constantly open to interactions with "other" subjects, adapted to the perception of a certain multitude of recipients. In other words, the "artistic image" as a process and result of the relations of an artwork and a specified multitude of recipients already contains a potential reference to its existence in the boundaries of the system of art, and therefore art criticism needs to "just" put this potential guidance into a verbal form. Simultaneously with the expression of this guidance, which is immanent to the artistic image itself, art critic produces its own reflection, which clarifies the mechanism of this selection and the scheme of actions of the recipient with the reference to the work of art.

The art critic also carries out "self-correction" of judgments by mental reconstruction of the boundaries of the variations of the artistic image in its extrapolation on participation of another possible recipient. In the process of consumption of art two subjects interact - the work of art-object and the viewer, that clearly choose each other, recognizing or denying standards in each other, carrying out the reflection of the search and selection. The consumption is mutual, as the need for the viewer and the need for the work of art are essential for reflection to take place. In addition to the choice of the standard, reflection is also associated with dealing with standard that should be carried out, and for this the artwork as an object offers a definite path to the transcendental subject of cognition. Thus, there are generalized universal "rules of the game", rules of dialogue, relationships with the work of art, and the acquisition of these recipes is the result of reflection on the action scheme mechanism of the standard. Inside the very process of crystallizing the artistic image takes place the process of creating the ideal. This subject is also determined by the area of extrapolation of the schemes of actions of the recipient with the standard, since the very formation of the artistic image (the result of reflection on the artwork-object and the viewer) involves unfolding of index replicas of the artwork-object (giving signs to the viewer-observer) into the iconic space of their conversation. Then their dialogue moves on to the symbolic level of familiarizing the viewers with the creation, when as a co-creator the viewer brings the experienced schema of action with the standard to his/her relationships with the world, making conclusions about his/her own boundaries in relationships with "others", thus learning about himself through the work of art.

\section{CONCLUSION}


The main contribution of this work to the development of the subject can be considered creation the function of the text in art criticism as educational space.

Key features of art-criticism are the awareness-raising function, the education of the artist in collaboration with the art material, the function of education of the viewer in interaction with the work of art.

The awareness - raising function of art criticism means training the reader of the text to distinguish between the artistic quality and pseudoartistic.

The education of the artist in collaboration with the art material is the function of criticism, helping in the creative process in the form of advice, tips, creative ideas, problems and solutions. The "education" in the second and third case, is synonymous with such concepts as the phenomenon of the image presentation, formation of the essence. The master becomes the real artist through art criticism, delineating the image of creativity as a whole, creating a kind of formula of creativity.

Education of the viewer in interaction with the artwork represents the third step in ideal forming activities of the text of art criticism-this is the reflection on areas of extrapolating the knowledge about the standard. In other words, the viewer with the help of the artwork and the facilitation of art-criticism, acquires new boundaries of him/herself

The obtained results indicate that self-knowledge is present in the artwork itself, whose content undergoes multiple testing in the form of the audience - curious and inquisitive, in the mirror of interaction with which the artwork perfects the image, allowing it to live inside the system.

The present study makes a significant contribution to the development of such promising scientific direction as development of methodology of educational art-publicism.

\section{REFERENCES}

[1] Arslanov V. G., Western art studies of the twentieth century, Russia, 861 pp., 2005.

[2] Bazin J., History of art history: from Vasari to the present day, 547 pp., 2008.

[3] Il'beykina M.I., Koptseva N.P., Visual Anthropology as a relevant area of Cultural Studies, Humanities and Social Sciences, № 2, pp. 133-155, 2014.

[4] Zhukovskiy V.I., Koptseva N.P., The propositions of the theory of the fine arts, Krasnoyarsk, 2004. P. 257.

[5] Zhukovskiy V.I., Theory of Fine Arts, Krasnoyarsk, pp. 98, 2004.

[6] Koptseva N.P., Reznikova K.V., Refinement of the Causes of Ethnic Migration North Selkups Based on the Historical Memory of 
Indigenous Ethnic Groups Turukhansk District of Krasnoyarsk Krai, Bylye Gody, Russia, vol. 38, issue. 4, pp. 1028-1038, 2015.

[7] Koptseva, N.P.; Khizhnyakova, A.N.; Reznikova, K.V., Linguistic-Culturological Peculiarities of National Languages of the Northern People of the Krasnoyarsk Region, Journal of Siberian Federal University. Humanities \& Social Sciences, № 3, pp. 323-341, 2011.

[8] Libakova N.M., Sertakova E.A., Formation of Ethnic Identiy of the Indigenous Peoples of the North in Arts and Crafts on the Example of Bone Carving, Journal of Siberian Federal University. Humanities \& Social Sciences, № 4 pp. 750-768, 2015.

[9] Reznikona, K.V. Preservation and Transformation of Certain Aspects of the Traditional Way of Life of the Indigenous and SmallNumbered Peoples of the North, Living in the Settlements (Posyolki) of Turukhansk and Farkovo, Journal of Siberian Federal University. Humanities \& Social Sciences, № 6, pp. 925-939, 2013.

[10] Shestakov V.P., History of the history of art:. By Pliny to the present day, Moscow, 304 pp., 2008

[11] Turchin V. S., From the history of Western art criticism XVIIIXIX centuries: France, England, Germany, Moscow, 368 pp., 1987.

[12] Sedlmayr H., Art and truth. Theory and Method of Art History, St. Petersburg., 2000.

[13] Zhukovskiy V.I., Tarasova M.V., Smolina M.G., Mirkes M.M., Kistova A.V., Pimenova N.N., Bakhova N.A. The educational function of artistic culture. Krasnoyarsk, pp. 222, 2013.

[14] Shestakov V.P., The history of American art: in search of a national identity, M., 455 p., 2013.

[15] Esaulov I. A. Ekphrasis in Russian literature of modern times: the picture and the icon // Problems of historical poetics. 2001. № 6 pp.43-56. 